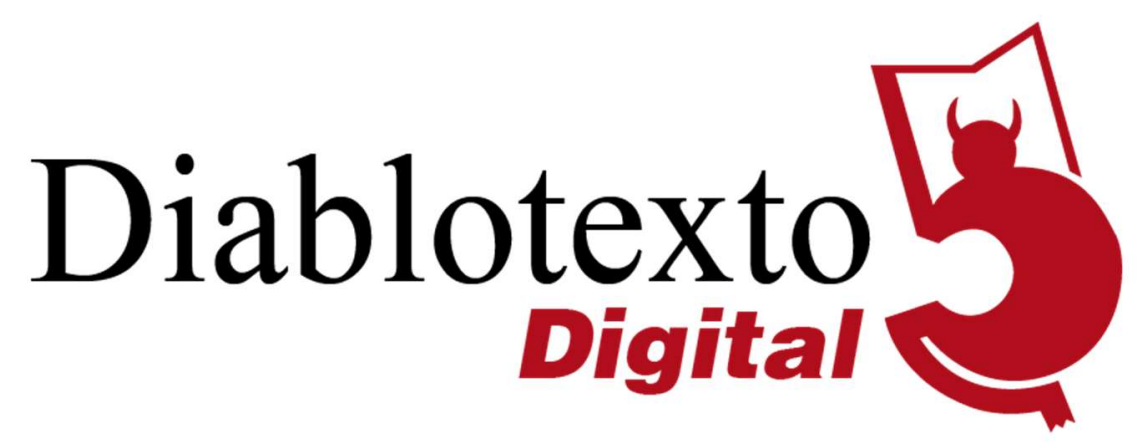

\title{
Amos y putos amos: nuevos lenguajes escénicos para nuevos Lazarillos
}

Bad Bosses and Badasses: New Theater Languages for new Lazarillos

\author{
CLARA MONZÓ \\ UNIVERSITAT DE VALĖNCIA
}

Resumen: Con su particular Lázaro (Leamǒk, 2019), Roberto Hoyo saca a escena el clásico narrativo del XVI como un pequeño canto en clave metadramática al oficio del teatro. Impulsora de un diálogo con las problemáticas sociales enraizadas en la generación Z, la obra constituye un camino de indagación hacia otros lenguajes. Las convenciones tradicionales abren paso a una preocupación por el ritmo que encuentra su cauce en la cultura hip hop, donde música y verso ofrecen nuevos vínculos con el patrimonio vivo de los Siglos de Oro.

Palabras clave: Lazarillo, teatro, hip hop, rap, Siglos de Oro

Abstract: With his peculiar Lázaro (Leamŏk, 2019), Roberto Hoyo brings back to scene the narrative classic from XVIth Century as a small metatheatrical ode to the acting trade. Enabling a conversation on social quandaries rooted in Gen Z, the play paves the way for a trip full of inquiries towards other languages. Traditional dialogues set the stage for a rhythm inquisitiveness expressed through hip hop culture, where music and verse provide new bonds with the living Spanish Early Modern heritage.

Key words: Lazarillo, Theater, Hip Hop, Rap, Spanish Early Modern

* Agradecimientos a Ángela Martínez Fernández y Purificació Mascarell, que han proporcionado a este Lazarillo su académico rigor. 
Bajando las escaleras, Lázaro me interpeló a mí, o eso decidí echando mano a mi derecho como espectadora, requiriendo espada. "Espero que a vuesa merced le flipe mi historia". Me hablaba o nos hablaba con el yo en la boca, muy rápido y con la muy descarada intención de contarnos su vida. Otro Lázaro en otro siglo llegó saltando la página hasta otros interlocutores que, más oyentes que lectores, atenderían a las venturas del sagaz mancebo. Quizá en el entonces del seiscientos, ante el ejercicio impuesto de la oralidad, el lector haría las veces también de intérprete, trasformando ante su auditorio la letra en ritmo; sin saberlo, dramatizando, o tal vez sabiéndolo, como asume cada uno su papel en el malquisto teatro del recitado en voz alta. Asisto pues a este tablado como me gusta imaginar que escucharían en la venta de Juan Palomeque la narración de El curioso impertinente, reunidos en torno a una mesa larga, larga y probablemente tan vacía como el estómago del joven lazarillo, como el espacio escénico que me ofrece Roberto Hoyo: atentos, flipados.

Roberto Hoyo (Valencia, 1996) es dramaturgo, es joven e insinúa haberse acercado al texto anónimo no desde el enfrentamiento sino desde la libertad y la intuición ${ }^{1}$. El Lázaro que presenta con su compañía, Leamǒk, y que ha pisado con buen pie la senda de los galardones, cuenta con la duración aproximada de un capítulo de Netflix: 35 minutos $^{2}$. Sin embargo $-\mathrm{y}$ aquí tiendo un tímido lazo al academicismo preceptivo—no emplea en toda la obra, por ejemplo, los controvertidos términos de "pícaro" y "picaresca" ${ }^{3}$. Es listo, como su personaje,

\footnotetext{
1 Salvo que se señale explícitamente, las declaraciones de Hoyo insertas a lo largo del artículo provienen de una entrevista - inédita- con el dramaturgo.

${ }^{2}$ La obra fue la ganadora del III Premio de Dramaturgia en la IX Edición del Festival Russafa Escénica. El jurado ponía de relieve en su deliberación "la innovación absoluta en el lenguaje escénico, por el contraste de lenguajes de textos clásicos y actuales, y por la posibilidad de investigación desde un punto actoral y dramatúrgico" (http://www.artezblai.com/artezblai/lazarode-roberto-hoyo-iii-premio-de-dramaturgia-russafa-escenica.html [Fecha de consulta: 10-32020]). En calidad de intérprete, muy recientemente ha sido nominado a mejor actor en la categoría Premi Crisàlide millor actor/actriu revelació en los Premis d'Actors i Actrius Professionals Valencians, pendiente de fallo.

${ }^{3}$ Es cuestión polémica la afirmación de un carácter precursor - tradicionalmente otorgado a la obra- de unos rasgos que se consolidarían en el Guzmán, frente a la consideración del Lazarillo como primera novela picaresca, tal y como planteó Rico (1973) en su célebre La novela picaresca y el punto de vista. Este debate trae aparejada una recepción compleja y una vasta producción bibliográfica de largo alcance. Así lo advertía Morros: "Las interpretaciones del Lazarillo son tan antiguas como la misma novela; pues como interpretaciones deben entenderse, por ejemplo, las novedades (título, epígrafes, división en capítulos...) que la edición príncipe introdujo en el manuscrito que llegó a manos del impresor [...], o las interpolaciones del texto de Alcalá [...]"
}

Diablotexto Digital 6 (2019), 79-100. 
sabe cómo hacer que asintamos los filólogos. Del de Tormes coge por lo tanto el fondo y lo despoja de la forma, no sin antes penetrar en el concepto de la propiedad o del decoro para pertrecharse de un conocimiento más profundo de lo que está dispuesto a reconocer. He ahí, al cabo, una dramaturgia.

Aunque renuncio a enzarzarme en la querella de lo antiguo y lo moderno a vueltas con la pertinencia de la adaptación de los clásicos, el Lázaro de Roberto Hoyo sacude una batería de puntos críticos de los que no siempre salimos bien parados; nosotros, esa voz de autoridad a quien se reserva el privilegio de ocupar un espacio como este. Mascarell sintetiza las raíces de un enfrentamiento todavía al alza:

El conflicto moderno entre el bando de las Letras y el del Teatro, perfilado durante la época de las vanguardias históricas y su concepción del teatro como un arte autónomo e independiente del resto de artes (incluida la literatura), ha producido dos clases de oponentes ya tópicos: el filólogo que condena e invalida las representaciones teatrales que transgreden la lectura académica y canónica del texto, por un lado, y el teatrero que detesta cualquier injerencia u opinión del estudioso y desconfía radicalmente de la academia, por otro (2014: 22).

En esta dirección, los puntos críticos pueden concretarse en los siguientes: la legitimidad de custodiar a los clásicos desde la tribuna; los vínculos de poder establecidos entre los estudiosos y los agentes (activos) teatrales; la circunscripción del concepto de clásico (áureo) a unos moldes teóricos y una mirada escénica proyectada en sentido reconstructivo; la fijación de un lenguaje poético y rítmico — con aplicación escénica - acomodados a un canon y unos modos culturales irradiados desde un núcleo académico más o menos hermético; o el entramado comercial que sostiene el oficio del actor. Sobre el último ítem no tengo otra potestad que la que me otorga el hecho de tener un hermano actor que partió a la capital para hacer fortuna en los escenarios. En cuanto al resto, es necesario emprender una indagación en lenguaje poético de la contemporaneidad que parta de la escena y halle su refuerzo, en la medida

([1987] 2006: 151). En el estado de la cuestión de su tesis doctoral, Restrepo Ramírez (2016) ofrece una práctica revisión de los pródigos caminos que la crítica ha tomado en sus lecturas del Lazarillo. Véanse, por lo tanto, sus apartados inaugurales (especialmente, las páginas 13 a 35) para componer un mapa de la extensísima tinta vertida en torno a la picaresca. Es apropiada, en el contexto de este artículo, la apreciación que el autor realiza en las primeras páginas (2016: 12): "el teatro, precisamente, ha sido el gran olvidado en la historia de la picaresca". 
de lo posible, en los fundamentos teóricos proporcionados por la filología o la semiótica del teatro.

En virtud de lo anterior, el objetivo principal de este artículo no es establecer una comparación entre original y puesta en escena -aunque esta se aborde en el proceso-, sino analizar la dramaturgia de Hoyo como punto de partida para lanzar una serie de reflexiones en torno a tres claves: la (re)lectura de los clásicos, la situación y el papel del teatro contemporáneo a través de la exploración de nuevos lenguajes escénicos y el intercambio de los espacios culturales ocupados por el rap y la poesía.

\section{“Dejé de tener amo para ser el puto amo". El Lazarillo para la generación Z.}

En términos de fábula, los paralelismos son claros. La obra se articula en torno a la figura del antihéroe homónimo, un muchachito que cae simpático por mucho que a través de su desgracia nos muestre las costuras de la estratificación social ${ }^{4}$. Al fin y al cabo, si bien se evidencia la pervivencia de una estructura vertical fundada en lo económico, el desparpajo de Lázaro le ha permitido salvar unas dificultades heredadas desde el azar del nacimiento para trepar aferrado a las grietas de esa jerarquía. Sacrificio y bonhomía canalla; una golosina para el capitalismo.

En efecto, el protagonista nos habla en retrospectiva desde un estado de franca estabilidad, tras haber alcanzado su objetivo primero: medrar. Los significantes se han actualizado o acomodado al nuevo mapa de la urbe salvaje, tan despiadada con el anónimo como aquella. El catálogo de secundarios sustituye a escuderos y bulderos por narcos de tres al cuarto y policías que se ensañan ${ }^{5}$. Esta revisitación de la obra narrativa —que, vaya por delante, es en

\footnotetext{
${ }^{4}$ La evolución de la novela picaresca y su reconfiguración a través de la narrativa finisecular y moderna - con Pío Baroja o Camilo José Cela- hasta nuestros días se enfrenta a la laxitud del término pícaro, una vez abstraído del contexto socioliterario del XVII: "Ahora bien: al surgir poderosa la burguesía en el siglo XIX español, estableciendo entre la clase alta y la baja el ancho y movedizo vado del dinero, la separación antigua fue borrándose. Siguió habiendo pícaros, pero no sólo entre los que aspiraban a subir, sino entre los que se vieron descendidos y entre los que procuraban mantenerse a flote. De otro lado, recuérdese que ya el pícaro antiguo acusaba con frecuencia como peores que él a miembros más felices o elevados de la sociedad de su tiempo. El pícaro de anteayer es, por consiguiente, equiparable al golfo de ayer y de hoy" (Sobejano, 1964: s. p.).

${ }^{5}$ Lázaro sirve a un escudero y un buldero, respectivamente, en los tractados tercero y quinto. Además, sobrevivirá bajo el ala de un clérigo, un fraile de la merced, un capellán o un alguacil.
}

Diablotexto Digital 6 (2019), 79-100. 
realidad un mero pretexto para la conformación de una visión dramatúrgica particular - incide sobre las claves que rodean la polémica al respecto de la adaptación de los clásicos: podar, recortar, modernizar el aparato léxico o trasladar la estética a una geografía más próxima a la del espectador; mecanismos que le permitan salvar la distancia con el original pero alcanzar, al mismo tiempo, una lúcida comprensión de la contemporaneidad anclada en problemáticas mundanas reconocibles. No es vacua misión. Así, la adaptación es, en todo caso, —y más allá de la laxitud del término fidelidad-muy libre, de forma que el texto narrativo, antes que reescribirse, ha servido de maleable inspiración. Ambos Lázaros convergen, de entrada, en el punto de partida de su crónica personal, la adopción de un molde monologado y, más profundamente, en esa proyección de una meta ascensional cuya cumbre se cifra en un estatus profesional $^{6}$. Y es en este último punto donde, al cabo, comparten un núcleo de convicción dramática ${ }^{7}$.

De este modo, la organización macroestructural es afín y plantea un recorrido que se inicia con un nacimiento deshonroso y unos progenitores ausentes: "Cuando yo nací mi papá ya estaba muerto / no me serví dél para llegar a buen puerto, / mi mama no podía darme nada, / así que me dio una palmada y me dejó con un experto, / experto en mala vida, en rabia desmedida" Desde este origen, el personaje transita por una serie de episodios o aventuras urbanas, entre la calle y la sordidez de las habitaciones sin dueño, que progresivamente conforman un paisaje que se ajusta al determinismo social, un viaje a través del barrio ${ }^{9}$. Apenas en los versos inaugurales, Lázaro acomete un

\footnotetext{
6 Estos tres puntos se acomodan, con matices interpretativos, a los rasgos clásicos que enumeraba Lázaro Carreter (1972: 204-207).

7 Se trata de un concepto clave dentro de lo que Hormigón (1991: 73) denomina lectura contemporánea del texto de partida: "establece el significado y sentido del texto que vamos a proponer como discurso escénico a los espectadores concretos que serán sus receptores, y completarán su sentido y significación. Ello supone la definición vertebradora de un «núcleo de convicción dramática», que explica la razón profunda de nuestra lectura selectiva y de nuestro compromiso con ella. Igualmente establece los subrayados analógicos contemporáneos". Remito a Gómez Ruiz (2018) para el trazado de un panorama contrastivo entre las tendencias teóricoprácticas relativas a la adaptación teatral de textos narrativos en la escena contemporánea.

${ }^{8}$ Transcribo directamente del texto inédito que me ha facilitado Roberto Hoyo. El original combina libremente prosa y verso, de ahí que haya prescindido de numeración. Tanto en esta como en citas sucesivas, regularizo la ortografía.

${ }^{9}$ Es pertinente distinguir este esteticismo costumbrista de los matices aducibles a un realismo que plantea varios niveles de interferencia con respecto al contexto de recepción del Lazarillo:
}

Diablotexto Digital 6 (2019), 79-100. 
salto en el que pasa de niño a adolescente, una hábil elipsis narrativa que traslada alegóricamente la no existencia de la infancia convencional. En las primeras paradas reconoceremos a ilustres secundarios, como "el ciego", que interviene aquí, sometido a una anfibología que bebe del argot, convertido en drogadicto. El ciego de Hoyo es un camello que proporciona a Lázaro techo, colchón —también visitado por las ratas- y enseñanzas; un puñado de lecciones aprendidas a la fuerza desde la posición de víctima; bien a palos, bien a través de la experiencia iniciática en el mundo de la droga - "con 15 años me dio de probar el éxtasis"- El adolescente se vuelve pronto ducho en el manejo de este lenguaje-dominación y responde al ciego en sus términos - "esa misma noche lo dejé moribundo"- hasta que toma la resolución de abandonarlo y salir, solo, a la calle. Ceguera moral o prosaico colocón, ambos ciegos comparten ese egoísmo descarnado del superviviente o el villano: "Él era el diablo, yo su lacayo fiel, / si se enfadaba no me daba de beber, / pero yo me hacía vino con la mala uva dél'.

Con gracejo conceptista se recurre de nuevo a los dobles sentidos como un recurso lingüístico para la reinterpretación de referentes. En este caso, la imagen de la uva leída en clave metafórica desde la desviación de su significado, remite al archiconocido episodio ${ }^{10}$. El resultado en ambos casos es el mismo e incide en el aprendizaje vital del joven Lázaro, instruido a trompicones por fortuitas figuras de autoridad sobre las que recae el peso de su educación. Así, la chanza verbal permanece a lo largo de la obra con los dejes propios del gracioso áureo: "era una mañana normal, el ciego desayunaba resaca y cigarro como siempre y yo, como éramos pobres y no nos podíamos permitir el desayuno completo, lo pedíamos sin «des»".

\footnotetext{
"No hay inconveniente, pues, en calificar el Lazarillo de 'realista', siempre y cuando reparemos en que a propósito de nuestro libro el adjetivo no vale igual que aplicado a una obra trescientos o cuatrocientos años posterior. En primera instancia, el Lazarillo es realista porque pretende pasar por real: porque se nos ofrece como de veras escrito por un pregonero vecino de Toledo. Sólo en segunda instancia conviene usar el adjetivo en el sentido que el siglo XIX nos legó como punto de referencia inevitable: 'verosímil' [...]' (Rico, 2011: 129-130).

10 Como sin duda se recordará, esta escena pertenece al tractado primero. El ciego, experimentado y sagaz, descubre la estratagema que Lázaro había ingeniado para sisarle las uvas: “¿Sabes en qué veo que las comiste tres a tres? En que comía yo dos a dos y callabas". Cito siguiendo la edición de Rico, 2011: 21.
}

Diablotexto Digital 6 (2019), 79-100. 
La construcción etopéyica se abre a la autoasunción del prototipo, con unas características fácilmente rastreables en la tradición a la que mira: personaje de baja extracción, penurias económicas y la combinación de agilidad de palabra y un simpático candor; rasgos accionadores de una empatía a veces peligrosamente (por nuestra parte) condescendiente. En medio de un vaivén de contrastes, los gestos de solidaridad despuntan sobre la ilegalidad como medio de subsistencia del protagonista desclasado, que juega con ese paternalismo latente en el público para integrarlo como un mecanismo de manipulación patética: "Cerveza de la mala la bebemos tos juntos / ¿Os parece si brindamos? Pregunto. / Brindamos por los que estamos y por tos los difuntos. / Me llaman ladrón, yo digo presunto". Una vez se ha logrado la aprobación temprana, este Lázaro empieza a apartarse del anterior para reunir su propia antología de penurias. Sin embargo, bajo el filtro del humor — "Mi vida está inspirada en un chiste de Jaimito"- permanecen algunas ideas insistentemente fijas entre las que se perfila con especial claridad la de la violencia, tratada como un estigma o un mal que adopta disfraces diferentes: abuso institucional, maltrato físico, abandono, crueldad infantil o racismo. Esta violencia proteica es lo que Roberto Hoyo concibe como esclavitud, no siempre manifestada en actos de evidente vejación como los anteriores, sino diluidos en una idiosincrasia o un modus vivendi atenazado por la cultura de masas: "Vosotros pensáis que no tenéis amo. / En estos días todo el mundo es esclavo". La relación de dependencia, desde el vasallaje, el mecenazgo artístico o la sucesión de amos de Lázaro de Tormes se truecan aquí en otro tipo de sometimiento: a la tecnología, al dinero o a la cultura impositiva de, por ejemplo, el fútbol.

De todos modos, Hoyo no ha venido a darnos lecciones ni a volver contra el espectador una suerte de retrato malicioso. Si en algo difieren el Lázaro al que interpreta de su predecesor es en la elocuencia de su optimismo final. Mientras que el desenlace de aquel quedaba sujeto a una ambigüedad agridulce (Rico, 2011: 190-197) ${ }^{11}$, el proceso de medro de este Lázaro no ha concluido, 11 En el conocido y tan comentado final del Lazarillo, obtenido el puesto de pregonero, el
matrimonio que el arcipreste ha concertado entre Lázaro y una criada suya está envuelto en la
sospecha: "Mas malas lenguas, que nunca faltaron ni faltarán, no nos dejan vivir, diciendo no sé
qué y sí sé qué de que veen a mi mujer irle a hacer la cama y guisalle de comer" (Lazarillo, 2011:

Diablotexto Digital 6 (2019), 79-100. 
inconcreta todavía la cumbre de su carrera. Lejos de lanzar aspiraciones hacia el futuro, la meta puede darse por alcanzada si se considera que esta no consiste en otra cosa que estar en paz con el presente y abrazar la incertidumbre como un espacio de liberadora oportunidad; vencidas las ataduras, ser el puto amo. El final - "Tendréis noticias mías sobre adónde embarco"- conserva la evocación de aquel viaje a las Indias de don Pablos y se inserta en la corriente del tópico de la vida como travesía marítima (Azaustre y Casas, 2009: 67-68) ${ }^{12}$. El muchacho sin oficio ni beneficio, sin embargo, parece haber salido airoso de un camino de emancipación vehiculado a través de lo profesional.

La obra adquiere así una dimensión metateatral cuando se desvela como una sincera apología del teatro, una reivindicación del teatro más como profesión que como arte. Es en este punto donde la voz del dramaturgo se vislumbra con mayor transparencia. En el plano ficcional, mientras el de Tormes se había convertido en pregonero ${ }^{13}$, Lázaro encuentra su asidero en la interpretación, sobre la que se vuelcan tanto la promesa de una estabilidad económica como la culminación de un proceso de reinserción social que lo convierta en "gente decente": "empezamos a hacer teatro porque hay gente mayor con pasta y es más fácil robarles. Y luego nos moló". Al mismo tiempo, y aquí entra Roberto Hoyo como dramaturgo o como personaje, la elección profesional se superpone a la concepción del teatro como un cauce de expresión no constrictora de una identidad lírica que confía románticamente en la palabra. En los versos finales, pareciera que Lázaro y Hoyo hablasen al unísono: "Por fin estoy haciendo las

78). Sin embargo, en las palabras de cierre, Lázaro declara hallarse "en la cumbre de toda buena fortuna" (2011: 80).

${ }^{12}$ De la promesa de una segunda parte nace el reciente cómic El Buscón en las Indias (Ayroles y Guarnido, 2019). En este caso, no se trata de una adaptación, sino de la creación de una continuación ficticia que toma el relevo de su antecesora. El trasvase de la narración a un signo historietístico (Monzó, 2019: 311) se enfrenta a otro tipo de obstáculos que los generados en el proceso del paso a la escena; pero los niveles de interferencia, en este caso, se asumen como parte del juego ficcional. No de otro modo la cita de Don Quijote que los autores han seleccionado para inaugurar la obra esté firmada por Pierre Ménard.

13 "Y pensando en qué modo de vivir haría mi asiento, por tener descanso y ganar algo para la vejez, quiso Dios alumbrarme y ponerme en camino y manera provechosa. $Y$ con favor que tuve de amigos y señores, todos mis trabajos y fatigas hasta entonces pasados fueron pagados con alcanzar lo que procuré, que fue un oficio real, viendo que no hay nadie que medre sino los que le tienen. En el cual el día de hoy vivo y resido a servicio de Dios y de Vuestra Merced. Y es que tengo cargo de pregonar los vinos que en esta ciudad se venden, y en almonedas y cosas perdidas, acompañar los que padecen persecuciones por justicia y declarar a voces sus delitos: pregonero, hablando en buen romance" (Lazarillo, 2011: 77).

Diablotexto Digital 6 (2019), 79-100. 
cosas a mi manera"14. La obra puede así leerse como un ejercicio de autoficción, pero siempre desde la precaución a la que insta De la Torre Espinosa (2017: 534): "En el teatro, pues, se hace imprescindible la presencia de un cuarto elemento para que se dé la autoficción, es decir, debemos ser conscientes de la coincidencia del autor dramático, el director de escena, el actor y el personaje" 15 . Aquí, el espectador asiste a la historia de Lázaro, de modo que la detección de las coincidencias entre dramaturgo y personaje se plantea en la interpretación posterior, pero aquellas no necesariamente se perciben desde la inmediatez espectacular.

El montaje de Hoyo no tiene entonces vocación de adaptación, tampoco de relectura; pero tal vez esta mirada de apropiación sin ataduras sea precisamente lo que le ha permitido detectar las conexiones esenciales con la obra y apostar por el vínculo humano con el espectador. La asunción del artificio del espectáculo y el planteamiento de un nuevo cauce rítmico -que abordaremos más adelante- esconden un respeto al original que no es al cabo sino el placer arbitrario que entraña la lectura personal de un libro. Sin pretenderlo, se logra una función ejemplarizante que se aviene con esa inherencia de la inmortalidad que atribuimos en fin a los clásicos y que genera unos vínculos de empatía capaces de vencer la distancia de los siglos. En un contexto de parámetros más divulgadores, las anteriores consideraciones recuerdan a las que subyacen en la propuesta dramatúrgica del auto sacramental El gran mercado del mundo llevada a cabo por la Compañía Nacional de Teatro Clásico la pasada temporada 2018-2019. Además de un planteamiento escenográfico a medio camino entre una colorida extravagancia —sello estético particular del montaje- y la abstracción conceptual que exige

\footnotetext{
${ }^{14}$ Estas declaraciones de Lázaro concuerdan con las emitidas a los medios por Hoyo: "Lázaro es mi manera de decir que estoy aquí, que los jóvenes existimos, nos lo pasamos muy bien, tenemos nuestro propio estilo y lucharemos por lo que queremos: vivir de esto" (https://www.levante-emv.com/cultura/2019/09/24/roberto-hoyo-gana-iii-premio/1925323.html [Fecha de consulta: 10 de marzo de 2020]).

${ }^{15}$ Y prosigue: "La autoficción teatral consistirá en una narración homodiegética donde asistimos a la coincidencia en la misma persona del dramaturgo, el autor del texto, el actor y el personaje, y donde lo narrado encuentra acomodo entre el pacto biográfico y el pacto de ficción" (2017: 534). De la Torre Espinosa se ocupa de la traslación del concepto de autoficción desde la narrativa al cine documental y el teatro donde, tal y como advierte, se subvierte el principio de la denegación teatral definido por Ubersfeld (2017: 535).
}

Diablotexto Digital 6 (2019), 79-100. 
un género dramático como este —tan hermético para el espectador contemporáneo-, se abogó por alternar el texto calderoniano con números musicales cuyas letras, bajo los moldes líricos más satíricos de la poesía áurea, encaraban conflictos específicos de una pretendida clase media. En estos términos se expresaba Xavier Albertí, director:

Los autos sacramentales de Calderón, tan atentos a los seísmos que prepararían las bases de una Modernidad aún eurocéntrica, interpelan muy directamente a nuestra contemporaneidad, con las nuevas y profundas transformaciones que nos ha tocado vivir (2019: 15).

El hecho de que en el seno de una compañía teatral volcada en una tarea de gran peso pedagógico para con la difusión de los Siglos de Oro tengan cabida pronunciados alejamientos con respecto a la ontología fundamental del auto sacramental —destinado muy específicamente a la exaltación de la eucaristíay que al auto se lo siga llamando auto, refuerza una concepción de los clásicos no subsumida a la rigidez de lo formal. $O$, en cualquier caso, mueve a repensar las fórmulas aprendidas y consagradas en escena a partir de la transmisión de unos tópicos - literarios, escénicos- que, precisamente por serlo, resultan permeables a otros lenguajes que vengan a intersectar con la ductilidad del signo teatral y mantengan activa y vital la comunicación con el espectador.

El análisis de montajes contemporáneos constituye una de las claves tanto para desanclar los estudios áureos de una tendencia teórico-reconstructiva de la puesta en escena, como para mantener y comprender el teatro desde su significado espectacular. La justa revalorización de la escena actual como objeto de estudio pasa por la exploración de los mecanismos de actualización junto con la adopción de un lenguaje de análisis de las especificidades de la teatralidad una perspectiva, no siempre certera, emprendida por la semiótica del teatro en la configuración de un signo teatral ${ }^{16}$ _, que garantizan la pervivencia de la comedia más allá del texto. De nuevo, Mascarell arremete contra la grieta entre

16 Bobes Naves (1997) emplea la etiqueta signo dramático. Sin poder detenerme más en el apartado de la semiótica o la semiología teatral, en ámbito hispánico son referentes, además de la autora, Romera Castillo (1990; 2011), Díez Borque y García Lorenzo (1975). García Barrientos (2003) comulga con esta voluntad por proporcionar un lenguaje y unos mecanismos de análisis al teatro desde la intangibilidad de la puesta en escena.

Diablotexto Digital 6 (2019), 79-100. 
dos sectores tristemente alejados e insiste en una suerte de responsabilidad filológica que termine por salvarla:

la parcela de la recepción contemporánea del teatro clásico en general, y la de su puesta en escena en particular, siguen esperando una exploración en profundidad así como un proyecto de envergadura que aborde con método, rigor y un enfoque global esta materia (2014: 26).

“Me dije «perfecto, palante»". La dramaturgia de lo que mola y lo que hiere

A las diatribas relacionadas con el proceso de adaptación, se añade en esta ocasión un distanciamiento complementario aparejado al cambio de lenguaje que acarrea teatralizar un texto narrativo -en este caso, si se quiere, narrativo-epistolar-. Paradójicamente, el teatro parece seguir constituyendo un formato útil para la didáctica de aquellos géneros no pensados para la escenificación. La confianza en la heterogeneidad del signo teatral, cuajado de estímulos que funcionan simultáneamente en varios niveles, se toma como recurso esperanzado frente a la dificultad de la palabra escrita, obstáculo en la recepción de los clásicos en prosa por parte de los lectores adolescentes. Así, se espera que ver en escena -o en pantalla - los textos que forman parte de un programa de lecturas obligatorias opere el salto mágico que, perdida la función del lector-demiurgo, debiere otrora producirse en el maltrecho arte de la imaginación. Una búsqueda rápida revela cómo el Lazarillo ha sido pródigo en su incursión escénica ${ }^{17}$. Y lo mismo sucede con otros títulos, fijos en la educación secundaria, tal y como ha estudiado Bastianes (2016) con respecto a La Celestina. El desajuste entre géneros, que implica la generación de unas expectativas de recepción claramente distintas, suscita otros interrogantes en los que no ahondaré aquí pero que tuve ocasión de tratar en otro lugar: "Queda aún por dilucidar si este tipo de producto funciona como un primer acercamiento a

\footnotetext{
17 Además de haber protagonizado un capítulo en la primera temporada de El Ministerio del Tiempo, el Lazarillo ha sucumbido incluso al fenómeno de las reescrituras de clásicos en clave zombi bajo el título LaZarillo. Matar zombis nunca fue pan comido (González-Pérez de Tormes, 2012). El seudónimo del autor, que figura así en portada, juega con el apellido de la novela original. Llosa Sanz (2017: 196) desgrana el fenómeno de reescritura de la zombificación, en cuyo seno el clásico adquiere tintes existencialistas: "Se puede interpretar entonces el Lazarillo canónico como un libro zombi, un libro de alma muerta por la falsedad histórica pero mantenido artificialmente vivo por una tradición institucional controladora que alimenta a sus lectores ingenuos hasta convertirlos en zombis culturales".
}

Diablotexto Digital 6 (2019), 79-100. 
los clásicos a fin de facilitar la profundidad de un segundo asalto o si, por el contrario, el lector dará por satisfecha su curiosidad" (Monzó, 2017: 44).

Progresivamente, la mirada transmedia y las adaptaciones modernas se han integrado con paso firme en los intereses de la academia, un incremento perceptible en las tesis doctorales consagradas a la cuestión que ya detectaba Mascarell en las primeras páginas de la suya (2014: 27). Por ejemplo, en los últimos años, dos importantes focos consagrados a los estudios áureos como son el Anuario Lope de Vega. Texto, Literatura, Cultura y el Anuario calderoniano han dedicado sendos volúmenes a las adaptaciones. De los artículos incluidos en el epígrafe "Calderón en las artes visuales contemporáneas" del volumen de 2016 de esta última revista, tres se ocupan de la obra del dramaturgo en el cine y la televisión. En esta línea, el número de 2018 de la primera lleva por título "La escena y la pantalla: Lope hoy". En las adaptaciones cinematográficas de la comedia nueva y la obra de Lope se ha especializado Carmona (2020).

Wheeler tantea las posibilidades pedagógicas de la aproximación audiovisual como herramienta de conocimiento y acercamiento a los clásicos en ámbito escolar, partiendo de la detección de un necesario revisionismo:

tanto la docencia como la producción televisiva y cinematográfica del franquismo han propagado una serie de prejuicios en cuanto al teatro clásico, una deuda con el patrimonio nacional que no se ha llegado a amortizar con la llegada de la democracia (2018: 263) ${ }^{18}$.

Rescatando la génesis metateatral de la obra de Hoyo, la dramaturgia se enfrenta a la noción del signo teatral desde la confianza en la dimensión eminentemente verbal. Esto comulga con la búsqueda de una puesta en escena sobria, de la que se han desterrado aquellos signos visuales que se afirman en efectos de iluminación. La generación de significados recae así sobre dos elementos: el actor y los signos sonoros, dentro de los cuales la música cobra una indiscutible relevancia, como veremos. La delimitación de las coordenadas escénicas espaciales depende de los desplazamientos actorales en combinación con el decorado verbal. No hay por lo tanto una correspondencia entre espacio ficcional y espacio físico o referencial, ni el espectáculo se sostiene

\footnotetext{
${ }^{18}$ Este trabajo incluye un crítico escrutinio del canon de autores áureos fijado en la enseñanza obligatoria a través de las sucesivas reformas educativas que, una vez más, nos deja en un lugar poco halagüeño con respecto al teatro isabelino.
}

Diablotexto Digital 6 (2019), 79-100. 
en la elocuencia escenotécnica, en virtud de un topos dúctil que se transforma con el intérprete. Los elementos de atrezo son reducidos y manejables: un mechero, una bolsa de deporte de la que se sacarán ciertos objetos ilegales y una litrona que circula entre los asistentes. Esta propuesta deja traslucir varios condicionantes: primero, la necesidad de abrazar una austeridad estética ante la limitación de medios económicos y las dificultades que entraña insertar un montaje en el entramado de la industria teatral contemporánea. En reinterpretación poética de la precariedad, tal circunstancia vuelve bululú al actor, quien asume ya no solo el peso de la función semiótica al erigirse como generador principal de significados, sino también las competencias propias de agentes adyacentes, al absorber una responsabilidad que excede el acto creativo y que abarca las tareas de gestión y distribución.

Segundo, las anteriores limitaciones se reaprovechan para plantear una poética encaminada a eliminar capas de alejamiento con respecto al espectador, al asimilar el espectáculo despojado de ornamentos como presentación sincera. Así, en lugar de abogar por un falseamiento esteticista, se evidencian las carencias - "enseñamos lo que somos", dirá Hoyo-; una maniobra que resulta en la percepción del montaje como un manifiesto. Lázaro nace de los recursos de los que se dispone, que son los mínimos, y se aleja de las convenciones dramáticas no como acto de subversión teórica sino por necesidad y desenfadada preferencia. En consonancia, la obra logra ofrecerse al público en forma de vistazo a ese lugar que las dramaturgias jóvenes o nuevas han sido conminadas a ocupar, al sortear como el Lazarillo los obstáculos de la estructura profesional para ampararse en la libertad creativa. Es cierto, al mismo tiempo, que este triunfo de lo austero se enfrenta al riesgo de sucumbir a esa trampa neoliberal que consagre la precariedad como estética y convierta la necesidad en tendencia artística $^{19}$. Pero dejando de lado las implicaciones político-

\footnotetext{
${ }^{19}$ En cierto sentido, esta puesta en escena reducida a los elementos esenciales no está alejada de la tradición del teatro pobre de Grotowski, al menos en sus más básicos presupuestos y en relación con la concentración del teatro en la figura del actor, despojado de estímulos accesorios. Recordemos sus palabras: "Eliminando gradualmente lo que se demostraba como superfluo, encontramos que el teatro puede existir sin maquillaje, sin vestuarios especiales, sin escenografía, sin un espacio separado para la representación (escenario), sin iluminación, sin efectos de sonido, etc. No puede existir sin la relación actor-espectador en la que se establece
}

Diablotexto Digital 6 (2019), 79-100. 
económicas inherentes al espectáculo entendido como producto, la dramaturgia de Roberto Hoyo tiene un objetivo mucho más simpático: flipar.

Así pues, el optimismo del Lázaro ficcional impregna las capas de la obra y la retrotraen hasta su concepción misma. Un aura de disfrute que, pasando por encima de la problemática social que empapa la fábula, revierte de nuevo en la figura del actor con el fin de consolidar una recepción que se alcanza con facilidad, pues si hay algo que al espectador resulta evidente es que Roberto Hoyo está haciendo lo que le gusta. En términos dicotómicos y según las declaraciones del dramaturgo: "prima lo que me mola a las convenciones". Lo que mola consiste pues en desechar aquellas formulaciones de la tradición dramática que no encajen con la idea de un teatro disfrutable, que contagie al público su vitalismo allá donde se superponen actor y personaje; un ganapán afortunado. Esta dramaturgia del flipe exige establecer un público ideal determinado por un rango de edad afín a la de Lázaro. Una conexión que se basa menos en un contagio emocional —la contagion passionnelle de Ubersfeld ([1977] 1996: 41-42)— adscrita al patetismo aristotélico, como en el lenguaje escénico en sí. Al poner el énfasis en el artificio formal se pretende reconectar con un espectador joven en el espectro de la generación $Z$ a quien se habla desde el tablado en su propio idioma ${ }^{20}$. Y no se trata de filtrar el texto original con el fin de modernizarlo en una jerga adolescente; más bien, de reinsertar en el ámbito dramático un prisma de estímulos usualmente asociados a manifestaciones culturales de masas o bien atravesadas por una marca de clase que las confina al arte periférico.

Aunque se lo presupone alejado de las normas de este lenguaje o de determinados referentes, no se desdeña a un público de más edad, con quien se trazan unas relaciones basadas en expectativas dispares. En este caso, los

la comunión perceptual, directa, «viva»" ([1970] 1992: 13). No obstante, para Hoyo la música constituye un ingrediente indisoluble de su dramaturgia.

${ }^{20}$ La etiqueta generación Z comprende el grupo demográfico nacido entre los años 1994 y 2010. Se les atribuye un emprendedurismo del que adolecen los millenial, la generación anterior, y que concuerda con la búsqueda de un espacio profesional propio en el que tenga cabida la individualidad y que late en la obra de Hoyo: "Hay una generación que quiere salvar el mundo, pero todavía no sabe cómo. Han nacido o crecido en plena recesión, en un mundo azotado por el terrorismo, índices de paro galopantes y una sensación apocalíptica provocada por el cambio climático. Son más realistas que sus hermanos mayores" (Verdú, 2015).

Diablotexto Digital 6 (2019), 79-100. 
vínculos se refuerzan propiciando las ocasiones de interacción física o mediante interpelaciones directas que, abiertas a la laxitud de la improvisación, se registran en las acotaciones explícitas: "Mirando a alguien del público”, "LÁZARO le dice a alguien que le toque el hueco del pecho"; o "Coge a alguien del público y le enseña una llave"21. De todos modos, si bien no responde a un ejercicio de traducción juvenil, el argot de la urbe invisible termina por contaminar en ocasiones la propia voz dramatúrgica para colarse en algunas acotaciones: "Enciende el mechero. Ojitos de fumao". Puesto que sustancialmente la obra presenta forma monologada, el trabajo interpretativo requiere un desdoblamiento actoral que se construye sobre la caracterización verbal de los sucesivos personajes.

Planea sobre esta aproximación lingüística una cierta noción del decoro en sentido clásico, por el que el policía o "el Morocco" — “Ouais, bonne merde! J'ai que qualité mon pote!"- asumen a través de su jerga las expectativas sociales volcadas en un personaje representante de un colectivo y cristalizado sobre la escena en calidad de tipo dramático, sin individualidad desarrollada. Este "Morocco" toma el relevo de personajes como el moro, el negro o el guineo, que empiezan a conformarse a mediados del XVI, en el seno del teatro breve, como personajes caracterizados lingüísticamente por una jerga específica, asociada a la comicidad. Así, esta construcción sostenida desde el punto de vista del habla encaja con las consideraciones sobre el decoro que Cervantes deslizaba en la advertencia al lector de su Prólogo a los entremeses: "[...] el verso es el mismo que piden las comedias, que ha de ser, de los tres estilos, el ínfimo, y el que el lenguaje de los entremeses es propio de las figuras que en ellos se introducen" ([1615] 2005: 94) $)^{22}$.

21 Dado que el texto original es todavía inédito, las acotaciones quedan a sujetas a futuras
variaciones.
22 Fundamentalmente con Lope, el moro se desarrolla y se escinde en múltiples vertientes,
totalmente aisladas ya, en sus propuestas más refinadas, de la función de soporte cómico.
Consúltese la entrada moro en el Diccionario crítico e histórico de la práctica escénica en el teatro
de los Siglos de Oro (DPESO) para un comentario histórico-lingüístico. Sobre las características
de la jerga morisca en Lope, así como para una síntesis de la bibliografía clásica, véase Belloni
(2012). Las consideraciones de la autora bien pueden aplicarse al "Morocco" de Hoyo: "La jerga
con la que el personaje suele expresarse en la escena es un elemento que lo identifica
visiblemente como sujeto periférico, como individuo «otro». El personaje del morisco nunca habla
un perfecto castellano, siempre se expresa a través de su característica jerigonza: para la Diablotexto Digital 6 (2019), 79-100. 


\section{"Te quito las esposas si me das la mano". Rap, teatro y lenguajes rítmicos.}

"La palabra puede volver a brillar". Hoyo confía en el verbo y en el verso como herramientas que vienen a salvar al teatro de un hermetismo que, desde su punto de vista, lo han desconectado de esa generación de espectadores a quienes se dirige. Si la escena está vacía y se ha prescindido de efectistas signos visuales, el vínculo con el público descansa en un elemento que constituye la piedra angular de su dramaturgia: la asunción de la música como lenguaje escénico. El primer paso será ampliar el bululú y hacerlo ñaque. Así, Lázaro tiene por compañero de aventuras a Marco Ferreira, cuyo papel principal es el de técnico de sonido y $d j$, pero que en ocasiones funciona como oportuno contrapunto del protagonista, al corear los pasajes en los momentos álgidos o interrumpir momentáneamente el monólogo. Ingrediente constitutivo de la obra, Marco y su mesa de mezclas forman parte del todo espectacular y responden a la misma intención de evidenciar el esqueleto teatral. El conjunto de efectos sonoros y musicales se activan a voluntad, reclamando para sí la autoría y poniendo de manifiesto el tejido ficcional ${ }^{23}$.

Al fin, ese idioma que acomete las fronteras generacionales y sitúa la palabra en el centro de una reflexión sobre la ontología del arte verbal halla su molde en el rap ${ }^{24}$. Es este género musical el que articula coherentemente las inquietudes del dramaturgo, un campo donde encuentra los instrumentos de expresión para aunar el poso de la tradición literaria con una preocupación por el ritmo. En los parámetros de la cultura hip hop, la expresión rítmica aflora en el

creación de esta lengua literaria, Lope se basa en la observación de la realidad cotidiana y vuelve a proponer el argot examinado en clave cómica" (2012: 105-106).

${ }^{23}$ En Tirant (2019) —adaptación de la obra homónima coproducida por l'Institut Valencià de Cultura y la CNTC y dirigida por Eva Zapico- la música y el espacio sonoro estaban a cargo de Kike Gasu, que desempeña un papel equivalente al de Marco Ferreira al situarse en escena visible al espectador, abandonando además en ocasiones el parapeto de la mesa de mezclas para intervenir con números de beat box.

${ }^{24}$ Una completa composición de lugar traza para Vice Madjody (2018). En este artículo se abordan las causas del auge del rap en el panorama musical de España experimentado en las últimas décadas, al tiempo que se definen y ejemplifican las diferentes ramificaciones del género, trap, música urbana $y$ su contacto con el dancehall o el reggaetón: https://www.vice.com/es latam/article/gynygm/del-rap-a-la-musica-urbana-en-espana-los-anosque-cambiaron-el-juego [Fecha de consulta: 10 de febrero de 2020].

Diablotexto Digital 6 (2019), 79-100. 
cuerpo del actor a través del breakdance ${ }^{25}$. La innovación, por lo tanto, es formal, y pone el foco en los significantes partiendo de un doble asidero: el interés por el acto performativo en sí, y el realce de la forma como puerta de entrada al contenido. El breve artículo de Santos Unamuno es fundamental para comprender cómo se ha efectuado la asimilación de un género tan caracterizado por índices de oralidad y performatividad en la materialidad de la escritura - aun aunque se transgreda la propiedad ortográfica-:

los autores de canciones rap atribuyen a sus creaciones una intención y un valor declaradamente artístico, seguros de hallarse inmersos en el devenir de los géneros poéticos. Esta autoconciencia es bien visible en el uso constante de palabras como "métrica", "lírica", "verso", "poesía" y, sobre todo, "rima", la palabra clave del universo rap (2001: 239) 26

De este modo, teniendo en cuenta que la práctica del rap conlleva un aprendizaje de las técnicas compositivas, el potencial didáctico es tentador. Jiménez Calderón señala la pertinencia del rap como objeto de estudio para la filología, dadas sus características literarias (2012: 167) y en el seno de una apertura auspiciada por los Estudios Culturales. Al amparo de esta disciplina se ha favorecido la transversalidad entre lo filológico y una "musicología más aguerrida metodológicamente" (Santos Unamuno, 2001: 236), que encierra un reajuste del concepto mismo de cultura. De hecho, Hoyo afirma haber accedido al arte lírico "de otro modo" a través del rap para dar, desde allí, con un impulsor que reconfigurase su visión dramatúrgica. El rap encaja en el proceso de cambio de la industria musical, menos dependiente de sellos discográficos o agentes externos en favor de la autoproducción. Volvemos así, de nuevo, al bululú. No obstante, la cultura hip hop puede alardear de ser social: "en su punto más vivo, está en la gente que se reúne en un parque a rapear, por amor al hecho en sí”27. La superposición con la condición del artista en los Siglos de Oro es tentadora. La aproximación al texto desde el ejercicio intelectual del

\footnotetext{
${ }^{25}$ El hip hop se considera, efectivamente, una cultura, cuyo surgimiento está ligado al grafiti y que combina, además, el baile, el dj y el MC (Ladrero, 2016: 107).

${ }^{26} \mathrm{Si}$ se aborda desde el punto de vista del ornatus, rap y poesía son pródigos en el uso de figuras retóricas, entre las que resultan vencedoras - en el corpus español— la metáfora y la aliteración junto con una notable preferencia por la intertextualidad (Jiménez Calderón, 2012: 176-178). Remito a este artículo para obtener un glosario básico de terminología del rap, así como un panorama sintético de las aproximaciones filológicas al campo (2012: 167-168).

${ }_{27}$ Declaraciones de Hoyo.
}

Diablotexto Digital 6 (2019), 79-100. 
desciframiento, erigida sobre el ensalzamiento de la opacidad como virtud, devuelve al lector, rapero o espectador una confianza en su predisposición al reto, a partir del deslumbramiento ante la forma o el artificio. Una oscuridad concomitante con la que defendía Góngora (1613) al respecto de sus Soledades:

pues si deleitar el entendimiento es darle razones que le concluyan y se midan con su contento, descubierto lo que está debajo de esos tropos, por fuerza el entendimiento ha de quedar convencido, y convencido, satisfecho. Demás que, como el fin del entendimiento es hacer presa en verdades [...] en tanto quedará más deleitado cuanto, obligándole a la especulación por la obscuridad de la obra, fuera hallando debajo de las sombras de la oscuridad asimilaciones a su concepto.

En cierto modo, la pluma y la espada emergen en la figura del rapero en la medida en que aúna o contrarresta los obstáculos consustanciales a las coordenadas de la calle con la práctica de la lírica. Para bien o para mal, la pérdida progresiva de un discurso marcado, circunscrito a reivindicaciones raciales, ha facilitado la entrada de la cultura europea, que ha recibido el género ya consolidado en forma de estética. Ladrero concreta con lucidez las causas remotas de este proceso de desintegración:

Pero bajo esas rimas y una actitud ceñuda se escondieron, también, funestas contradicciones, en las antípodas de la revolución que algunos líderes afroamericanos habían soñado para su pueblo. El capitalismo era competitividad e individualismo, atributos a los que el hip hop pocas veces quiso renunciar, a sabiendas de que el racismo era, sobre todo, fruto de la desigualdad económica y pese al asombroso talento de los autores de las rimas para golpear de frente. Ostentación y demagogia (2016: 126).

Por otra parte, este vaciado del rap hacia su asentamiento como fórmula artística corre en paralelo a la del fenómeno poético editorial de los últimos años y suscita tal vez interrogantes análogos: ¿Se está produciendo una reestructuración de los agentes interventores en el hecho poético? ¿Es legítimo adscribir a la poesía un discurso subversivo en el momento en que los mecanismos de transmisión de esta voz son absorbidos por una editorial? ¿Es poesía la que ha sido escrita no para ser recitada sino leída? El triunfo de lo visual —consolidado en determinadas plataformas digitales - termina por confirmar la disociación de los géneros líricos de su función originaria. Ante la pervivencia de las preocupaciones humanas ancestrales cristalizadas en la 
literatura en forma de tópicos, cabe asumir que toda evolución, toda revolución rítmica, es una cuestión de forma y no de fondo. De ahí que la gran sacudida estética del siglo XVI español sea el resultado de la victoria de una nueva unidad métrica, el endecasílabo, sobre otra, el octosílabo. En cuestión de apenas medio siglo, lo que había empezado como un experimento de importación capitaneado por Boscán ha pasado a formar parte de la tradición, y Garcilaso, con sus estrofas de base endecasílaba, es ya el gran referente de la tradición lírica.

Quizá las batallas de gallos glorificadas en parques y parkings han venido a heredar el papel de las Academias, siquiera en la configuración de un espacio de creación colectiva, proclive a la improvisación y con un espíritu de enfrentamiento cordial donde el ingenio y el manejo de unas reglas rítmicas predefinidas son imprescindibles para el triunfo. Precisamente, frente a la popularización de unas manifestaciones poéticas vinculadas a lo visual y desposeídas de la conciencia auditiva originaria —especialmente en cuanto a la preocupación por la métrica-, cabe preguntarse si el rap no nos está ofreciendo una puerta a la didáctica de la poesía, en cuanto a herramienta de acercamiento al ritmo y la palabra, y que permite al mismo tiempo recuperar la lectura en voz alta o favorecer, en definitiva, la formación de una sensibilidad sonora que nos acerque a la concepción del arte y la música de los Siglos de Oro. Quizá la reconciliación de la poesía, el teatro y al fin los clásicos pase por repensar los espacios de autoridad cultural y redefinir las fronteras, no de la materia literaria, sino de los mecanismos de difusión y análisis. Sea como fuere, Roberto Hoyo recoge estas inquietudes en su Lazarillo particular y las lanza hacia la escena. La música - motor y lenguaje dramáticos — le permiten partir de la obra original para afirmar la libertad de su dramaturgia, una vez desasido de esos amos, y reivindicar con la práctica la posibilidad todavía alcanzable del teatro entendido no solo como arte, sino como profesión.

\section{BiBLIOGRAFÍA}

Albertí, Xavier (2019). “Descubrámoslos, escuchémoslos, leámoslos...”. En Mar Zubieta (ed.), El gran teatro del mundo. (s. I.): Ministerio de Cultura y Deporte/INAEM/CNTC, Programas Didácticos, 18, pp. 13-15.

AYRoles, Alain; GuARNIDO, Juanjo (2019). El Buscón en las Indias. Barcelona: Norma Editorial. 
AZAustre, Antonio; CASAS, Juan (2009). Manual de retórica española. Barcelona: Ariel.

BAstiAnes, María (2016). La Celestina en escena (1909-2012) [Tesis Doctoral]. Madrid.

BELLONI, Benedetta (2012). "«Que es gente que come arroz, / pasas, higos y alcuzcuz»: la construcción de la imagen esterotipada del morisco en nueve comedias de Lope de Vega". Anuario Lope de Vega, XVIII, pp. 80113.

BoBES NAVES, María del Carmen (1997). Semiología de la obra dramática. Madrid: Arco/Libros.

CARMONA, Alba (2020). Las reescrituras fílmicas de la comedia nueva: un siglo en la gran pantalla. Oxford: Peter Lang.

CARMONA, Alba et al (coords.) (2018). La escena y la pantalla: Lope hoy. Anuario Lope de Vega. Texto, Literatura, Cultura, 24.

Cervantes, Miguel de [1615] (2005). Entremeses, Nicholas Spadaccini (ed.). Madrid: Cátedra.

DíEZ BORQUE, José María; GaRcía LoRENZO, Luciano (dirs.) (1975). Semiología del teatro. Barcelona: Planeta.

GARCÍA BARRIENTOS, José Luis (2003). Cómo se comenta una obra de teatro. Madrid: Síntesis.

GómEz RuIz, María Soledad (2018). "Pautas sobre la adaptación de dramaturgos españoles del siglo XXI", Forma. Revista d'estudis comparatius, 17, pp. 68-83.

GóngORA, Luis de [1613] (2000). "Carta de D. Luis de Góngora en respuesta a la que le escribieron". En Antonio Carreira (ed.), Obras Completas, I. Madrid: Fundación José Antonio de Castro, pp. 253-260.

GonZÁlez-PÉREZ DE TORMES, Lázaro (2009). LaZarillo. Matar zombis nunca fue pan comido. Barcelona: Debolsillo.

GRotowSKY, Jerzy [1970] (1992). "Hacia un teatro pobre". En Hacia un teatro pobre, Margo Glantz (trad.). México: Siglo Veintiuno. pp. 9-20.

HoRmıgón, Juan Antonio (1991). Trabajo dramatúrgico y puesta en escena. Madrid: ADE.

JIMÉNEZ CALDERÓN, Francisco (2012). "El rap español en el ámbito de los discursos de especialidad". Pragmalingüística, 20, pp. 164-182.

LADREDO, Valentín (2016). Músicas contra el poder. Canción popular y política en el siglo XX. Madrid: La Oveja Roja.

LAZARILLO DE TORMES (2011), Francisco Rico (ed.). Madrid: Real Academia Española (Biblioteca Cásica de la Real Academia Española, 29).

LÁZARO CARRETER, Fernando (1972). "Para una revisión del concepto «novela picaresca»". En "Lazarillo de Tormes” en la picaresca. Barcelona: Ariel, pp. 195-229.

LLOSA SANZ, Álvaro (2017). "Del LaZarillo al Occupy zomby: zombificaciones literarias y sociales para un nuevo siglo". Impossibilia. Revista Internacional de Estudios Literarios, 14, pp. 187-212.

MADJODY (2018). "Del rap a la música urbana en España: Los años que cambiaron el juego". Vice, en https://www.vice.com/es latam/article/gynygm/del-rap-a-la-musica- 
urbana-en-espana-los-anos-que-cambiaron-el-juego [Fecha de consulta: 10 de marzo de 2020].

MAscaRell Purificació (2014). El Siglo de Oro español en la escena pública contemporánea. La Compañía Nacional de Teatro Clásico (1986-2011) [Tesis Doctoral]. València.

Monzó, Clara (2019). Poética de la acotación en la dramaturgia de Calderón de la Barca [Tesis Doctoral]. València.

Monzó, Clara (2017). “Don Quijote en el manga: traducción, transformación y adaptación en la cultura de masas japonesa". Trans: Revista Española de Traductología, 21, pp. 35-47.

MorRos, Bienvenido C. [1987] (2006). "Apéndice bibliográfico". En Lazarillo de Tormes. Francisco Rico (ed.). Madrid: Cátedra, pp. 147-168.

PronkeVICH, Oleksandr; Escudero BAZTÁN, Juan Manuel (coords.) (2016). Anuario calderoniano, 9.

Restrepo RAmírez, Santiago (2016). Las comedias de Lope de Vega en el desarrollo del género y la materia picaresca [Tesis Doctoral]. Universitat Autònoma de Barcelona.

Rıco, Francisco (1973). La novela picaresca y el punto de vista. Barcelona: Seix Barral.

Rodríguez CuAdros, Evangelina, (dir.), Diccionario crítico e histórico de la práctica escénica en el teatro de los Siglos de Oro (DPESO), en http://parnaseo.uv.es/Ars/ARST6/diccionario/inicio.html.

Romera CASTILLO, José (2011). Pautas para la investigación del teatro español y sus puestas en escena. Madrid: Universidad Nacional de Educación a Distancia.

Romera CAStILlo, José (1988). Semiótica literaria y teatral en España. Kassel: Reichenberger.

s. a. (2019). “'Lázaro' de Roberto Hoyo, III Premio de Dramaturgia Russafa Escénica", Artezblai, 24-9-2019, en http://www.artezblai.com/artezblai/lazaro-de-roberto-hoyo-iii-premio-dedramaturgia-russafa-escenica.html [Fecha de consulta: 10 de febrero de 2020].

SANTOS UNAMUNO, Enrique (2001). "El resurgir de la rima: los poetas románicos del rap". En Antonella Cancellier y Renata Londero (coords.), Atti del XIX Convegno dell'Associazione Ispanisti Italiani. Roma: Unipress, v. 2, pp. 235-242.

SoBEJANO, Gonzalo (1964), "Sobre la novela picaresca contemponánea”, Boletín Informativo de Derecho Político, 31, pp. 213-225. Recuperado de http://www.cervantesvirtual.com/obra-visor/sobre-la-novela-picarescacontempornea-0/html/02165fb8-82b2-11df-acc7-002185ce6064_3.html [Fecha de consulta: 10 de febrero de 2020]

TORRE ESPINOSA, Mario de la (2017). "La autoficción española como símbolo de la hipermodernidad: teatro y cine documental". En Luis AlburquerqueGarcía, José-Luis García Barrientos y Roberto Álvarez Escudero (eds.), Escritura y teoría en la actualidad. Actas del II Congreso Internacional de ASETEL. Madrid , 29-30 de enero de 2015. Madrid: CSIC, pp. 529-538.

UBERSFELD, Anne [1977] (1996). Lire le théâtre, I. París: Belin. 
VERDÚ, Daniel (2015). “La generación Z cambiará el mundo", El País, 3-5-2015, enhttps://elpais.com/politica/2015/05/02/actualidad/1430576024 684493. html [Fecha de consulta: 10 de febrero de 2020].

WHEELER, Duncan (2018). "Las adaptaciones cinematográficas como (posible) herramienta pedagógica". Anuario Lope de Vega. Texto, Literatura, Cultura, 24, pp. 260-287.

Fecha de recepción: 9 de enero de 2020

Fecha de aceptación: 31 de marzo de 2020 